Link article (Style APA): Kiparenko, O. L., \& Kremenchutska, M. K. (2021). Assessment of the impact of motor development on adaptation to learning. Insight: the psychological dimensions of society, 6 , 95-109. DOI: 10.32999/2663-970X/2021-6-7

Link article (Style DSTU 8302: 2015): Kiparenko, O. L., Kremenchutska, M. K. Assessment of the impact of motor development on adaptation to learning. Insight: the psychological dimensions of society, 2021, 6, 95-109. DOI: 10.32999/2663-970X/2021-6-7

UDC 37-044.332:796.011.3

\title{
Assessment of the impact of motor development on adaptation to learning
}

\section{Оцінка впливу рухового розвитку на адаптацію до навчання}

Received: July 30, 2021

Kiparenko Olena Leonidivna

Postgraduate student

Department of Differential and Special Psychology

Odesa I. I. Mechnikov National University, Ukraine

Elena.kiparenko@gmail.com

https://orcid.org/0000-0001-8577-0108

Kremenchutska Margaryta

Kostyantynivna

Candidate of Psychological Sciences, Associate Professor

Department of Differential and Special Psychology

Odesa I. I. Mechnikov National University, Ukraine mkk@ukr.net

https://orcid.org/0000-0002-8588-1016
Accepted: November 11, 2021

\section{Кіпаренко Олена Леонідівна}

Аспірантка

кафедра диференціальної

та спеціальної психології

Одеський національний університет

імені I. I. Мечникова, Україна

Elena.kiparenko@gmail.com

https://orcid.org/0000-0001-8577-0108

Кременчуцька Маргарита

Костянтинівна

кандидат психологічних наук, доцент

кафедра диференціальної

та спеціальної психології

Одеський національний університет

імені I. I. Мечникова, Україна mkk@ukr.net

https://orcid.org/0000-0002-8588-1016

\section{Abstract}

The article renders findings of the study of the development of school children's reading skills and motor development $(n=61)$. Pedagogical and psychological literature considers visual, auditory, and cognitive impairments as primary causes of difficulties in developing reading skills. It is generalized an idea that all types of perception (visual, auditory, etc.) are of afferent-efferent nature: each of these sensory processes is based on its own motor components. The purpose of the research is to analyze the impact of student's motor skills disorders on mastering reading skills; to

\section{Анотація}

У статтіпредставленірезультати дослідження сформованості навичок читання школярів та їхнього рухового розвитку $(\mathrm{n}=61) . \mathrm{У}$ педагогічній та психологічній літературі основними причинами труднощів формування навичок читання найчастіше визначають зорові, слухові та когнітивні проблеми. Розглянуто черговий чинник у структурі розвитку дитини - руховий розвиток. Узагальнено думку, що всі види сприйняття (зорове, слухове тощо) мають аферентно-еферентний характер, в основі кожного $з$ цих сенсорних процесів беруть участь свої 
find the root of the disorders using neuropsychological tests; to differentiate errors and identify effective correction methods. Research methods are as follows: O. Luria Neuropsychological Battery adapted to school children by Glozman J.; child dyslexia test by 0. Korniev \& 0. Ishymova. Research results have been processed through mathematical statistics, i.e., Pearson correlation coefficient and point-biserial correlation coefficient. Results. It has been identified the most significant indices of the functioning of the motor system of a child, which influence the progress of mastering reading skills in two age groups of school children (aged 7-9 and 10-12). The research has found the most fundamental errors made by school children while performing tests that are a ground for basic neuropsychological correction. Conclusions. It has been substantiated that reading is a multi-factor process, and helping a pupil under some reading difficulties. It cannot be limited to monotonous methods. The research states that neuropsychological diagnostics contributes to finding poorly-developed elements, which affect a child's learning, discovering errors, and developing an effective intervention plan. The first step of the correction should comprise the work with the child motor system, as proved by this research. It is noted that a sensorimotor correction based on M. Bernstein's construction of movements may underly the program.

Key words: neuropsychological diagnostics, dyslexia, learning difficulties, sensorimotor correction.

\section{Introduction}

Challenges of mastering reading skills in modern primary school are commonplace. The procedure of neuropsychological examination allows fixing the preconditions for various forms of dyslexia in older preschoolers. The problem can be elicited in the first form, and thus, it is difficult for a student to master almost the entire curriculum because well-formed reading skills are the basis for understanding texts not only in the humanities but also in mathematics. An adequate solution to overcoming such difficulties should involve determining the exact cause of their occurrence and subsequent intervention program, which relies on child stable, well-developed mental functions. There are the following types of dyslexia: optical, mnestic, phonemic, semantic, ungrammatical, regulatory, tactile (in blind children).

Neurological studies do not establish a real cause of child dyslexia, but clinical characteristics рухові компоненти. Метою дослідження $є$ визначення впливу рухових проблем школяра у оволодіння навичками читання; розуміння причини цих проблем за допомогою нейропсихологічних проб; диференціація помилок і визначення ефективних методів корекції. Методи дослідження: класична батарея нейропсихологічних тестів О. Лурії, адаптована до дітей шкільного віку Ж. Глозман; методика діагностики дислексії у дітей О. Корнєва і О. Ішимової. Здійснено обробку результатів методами математичної статистики, а саме - кореляційний аналіз за Пірсоном та точково-бісеріальних коефіцієнтів кореляції. Результати. Визначено найбільш значущі показники роботи рухової системи дитини, які мають вплив на успішність оволодіння навичками читання у двох вікових групах школярів (7-9 та 10-12 років). 3'ясовано найбільш значущі помилки при виконанні проб школярами, що $є$ підставою для базових напрямків нейропсихологічної корекції. Висновки. Обгрунтовано, що читання - багаточинниковий процес і допомога дитині при труднощах 3 ним не може обмежуватися одноманітними методами. Констатовано, що нейропсихологічна діагностика допомагає встановити чинники, які є несформованими і впливають на навчання дитини, диференціювати помилки i побудувати ефективний корекційний маршрут. Першим кроком корекції має бути робота з руховою сферою дитини, що доведено нашим дослідженням. Зазначено, що основою програми може бути сенсомоторна корекція на базі теорії про побудову і біомеханіку рухів М. Бернштейна.

Ключові слова: нейропсихологічна діагностика, дислексія, труднощі навчання, сенсомоторна корекція.

\section{Вступ}

Труднощі оволодіння навичками читання у сучасній молодшій школі - явище досить буденне. У старших дошкільників процедура нейропсихологічного обстеження дозволяє зафіксувати передумови до різних форм дислексії.У першому класі проблема простежується і далі школяреві важко опанувати навчальну програму практично з усіх предметів, тому що добре сформовані навички читання лежать в основі розуміння текстів не тільки гуманітарних напрямків, але i математичних. Правильне подолання таких труднощів можливе при визначенні точної причини їх виникнення та подальшої корекційної програми, яка буде

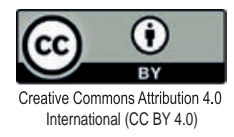


show that children often have the so-called "motor awkwardness", inaccuracy, difficulties of motion differentiation. At the same time, they have normal involuntary motor acts.

The nature of motor disorders in dyslexic children is not explicit: it is about more subtle disorders of praxis, i.e., purposeful movements and actions that do not allow a child to act in a school environment - however, children are coordinated enough and perform precise purposeful movements outside of school, in games of their interest.

The scientific literature contains hypotheses about morphological features of the cerebellum structure in children with dyslexia (GonzalezValenzuela, 2021), the relations of sensorimotor deficiencies and reading difficulties, and the correlation of motor images with reading difficulties (Walle de Ghelcke, 2021), as well as other studies which demonstrate the relevance of the issue under consideration.

There are many classifications of forms of dyslexia, and they are conditional enough: the disorder mechanism, a cause of difficulties, and the subsequent improvement of the disorder may not always be intelligible. The neuropsychological approach takes into account the principle of construction of mental function, its brain organization. In this context, a big part belongs to the neuropsychological factor, which is involved in the work of various mental functions, and its accurate diagnosis allows proceeding to a more profound analysis of the structure of the mental process. At firstglance, it is difficult to imagine that different psychological processes, e.g., spatial orientation, counting, and understanding of inverse logical and grammatical constructions, have common basis and links that can be combined with a common neuropsychological factor. (Luria, 2009).

0. Luria defined concepts of higher mental functions (memory, attention, perception, thinking, and language) as ideas about functional systems based on the morphological substrate of the brain (Glozman, 2020).

In neuropsychology, according to the principle of systemic building of higher mental functions of language involving reading, it is considered as acomplexfunctionalsystem, which comprisesmany components that rely on the operation of different базуватися на сильних, добре сформованих психічних функціях дитини. $Є$ такі види дислекciі: оптична, мнестична, фонематична, семантична, аграматична, регуляторна, тактильна (у сліпих дітей).

Неврологічні дослідження не встановлюють чіткої причини проблеми у дітей з дислексією, але клінічна картина показує, що у таких дітей часто спостерігається так звана "моторна незграбність", неточність, труднощі диференціювання руху, одночасно 3 цим мимовільні рухові акти у них у нормі.

Характер моторних порушень у дітей з дислексією не відкрито виражений, більше це тонкі порушення праксису, тобто цілеспрямованих рухів і дій, які не дають можливості дитині діяти в умовах шкільного навчання, в той час, як поза школою, в цікавих для них іграх, діти досить скоординовані і виконують точні цілеспрямовані рухи.

У науковій літературі $є$ гіпотези про морфологічні особливості будови мозочка у дітей 3 дислексією (Gonzalez-Valenzuela, 2021), про зв'язок недоліків сенсомоторного управління, труднощами читання і кореляції моторних образів 3 труднощами прочитання слів (Walle de Ghelcke, 2021) та інші дослідження, які показують актуальність до даного питання.

$€$ досить багато класифікацій форм дислекciї, вони досить умовні і не завжди нам будуть зрозумілі механізм порушення, причина труднощів і подальша корекція порушення. $\mathrm{y}$ нейропсихологічному підході враховується принцип побудови психічної функції, іï мозкова організація. Тут величезну роль відіграє нейропсихологічний чинник, який включений в роботу різних психічних функцій, і його точна діагностика дозволяє перейти до більш глибокого аналізування структури психічного процесу. На перший погляд важко уявити, що різні психологічні процеси, наприклад, орієнтування у просторі, рахункова діяльність i розуміння зворотних логіко-граматичних конструкцій мають загальну основу, загальні ланки, які можна об'єднати загальним нейропсихологічним чинником. (Лурія, 2009).

Уявлення про вищі психічні функції (пам'ять, увага, сприйняття, мислення і мова) були визначені О. Лурія як уявлення про 


\section{Kiparenko Olena, Kremenchutska Margaryta}

parts of the brain. Each of these components plays a special role, and the underdevelopment of any of them leads to specific complications in the formation of the entire function.

Luria noted that reading, like writing, is a specific form of language. This form differs in its genesis from expressive language; there are also differences in psychophysiological structure and functional features. Reading, as an activity, is organized and not formed automatically in communication between a child and an adult this process is the outcome of special training.

The development of reading skills can be commenced at thefirsthints of expressivelanguagethe selection of phonemes from the speech flow. The pivotal role in this process is performed by the secondary auditory (temporal) cortex of the left hemisphere, which has a high-powered system of connections with the postcentral and lower divisions of the premotor cortex. The postcentral divisions of the premotor cortex are also called kinesthetic. One of the functions is the synthesis of separate sensations into the whole structure, and their failure causes a deviation of the afferent block of the child's movement.

Expert observations of the Center for Practical Neuropsychology (Odesa, Ukraine) demonstrate that with the optimal selection of exercises for sensorimotor training of a preschooler, his impressive and expressive language goes from strength to strength. Older children (aged 7 and older) master reading skills much faster with the appropriate program of motor (sensorimotor) correction - almost $80.0 \%$ of cases of intervention activity confirm this fact. Parents say that after intervention activity, such improvement of schoolchildren's development is apparent in all directions of school training. The scientists have not studied other dimensions except reading.

The purpose of the article is to determine the impact of the student's motor disorders on mastering reading skills; to understand the causes of the relevant problems applying neuropsychological tests; to differentiate errors and identify effective intervention methods. The achievement of the purpose has required us to take the following measures:

1. To adapt the Ukrainian-language method of diagnosing dyslexia in children функціональні системи, основою для яких $\epsilon$ морфологічний субстрат головного мозку (Glozman, 2020).

У нейропсихології відповідно до принципу системної побудови вищих психічних функцій мови, в структурі якої $€$ читання, розглядається як складна функціональна система, до складу якої входить багато компонентів, що спираються на роботу різних ділянок мозку. Кожен 3 цих компонентів відіграє свою особливу роль, і недорозвинення будь-якого з них веде до специфічних ускладнень формування всієї функції в цілому.

Лурія відзначав, що читання, як і письмо, $\epsilon$ особлива форма мови. Ця форма відрізняється за своїм генезом від експресивної мови, також $є$ відмінності по психофізіологічній побудові і за функціональними особливостями. Читання, як діяльність, організовано і не формується автоматизовано в процесі спілкування дитини з дорослим, цей процес $є$ результатом спеціального навчання.

Формування навичок читання можливо при перший умові виникнення експресивної мови-виділення з мовного потоку фонем. Основну роль в цьому процесі відіграють вторинні відділи слухової (скроневої) кори лівої півкулі, які володіють потужною системою зв'язків з постцентральними і нижніми відділами премоторної кори головного мозку. Постцентральні відділи премоторної кори також називаються кінестетичними. Одна з функцій - це синтез окремих відчуттів в цілі структури, а їх поразка спричинить порушення аферентного блоку руху дитини.

Спостереження фахівців Центру практичної нейропсихології (м. Одеса, Україна) говорять про те, що при оптимальному підборі вправ з сенсомоторної корекції дошкільника імпресивна та експресивна мови у нього якісно поліпшуються. Більш старші діти (від 7 років) набагато швидше опановують навички читання при відповідній програмі рухової (сенсомоторної) корекції, це зазначається приблизно в $80.0 \%$ випадках корекційної роботи. Таке поліпшення розвитку школярів відзначається в усіх напрямках шкільного навчання після корекційної роботи, це зазначається за словами батьків, досліджень по 
(SMSRS - (Standardized Methodology for Studying Reading Skills).

2. To conduct a neuropsychological examination of children.

3. To establish correlations of neuropsychological factors in the motor sphere of a child and the level of mastering reading skills.

Hypothesis. The authors suggest that together with traditional speech therapy methods of dyslexia correction, it is possible to effectively use neuropsychological methods of sensorimotor correction for children experiencing difficulties in mastering reading skills after neuropsychological diagnosis.

\section{Methodology and methods}

The research is based on 0 . Luria Neuropsychological Battery and a traditional battery of tests. These methods are oriented towards the child's capacity, given the strengths and weaknesses of his development.

The further correction relies on A. Bernshtein's methodology and his theory of movement construction in which speech and reading are treated as the supreme levels of movement construction.

Research sample. Participants: 61 children from Kyiv and Odesa. The sample distribution is considered by age: 7 -years-olds - three; 8 years eleven; 9 years - seventeen; 10 years - sixteen; 11 years - nine; 12 years - five.

Two, almost equal, age groups have been formed: $7-9$ years $(n=31)$ and $10-12$ years $(n=30)$. These two groups have been predominantly analyzed.

Procedure and tools. The research was based on Luria Neuropsychological Battery adjusted to childhood by Glozman J., child dyslexia test by O. Korniev \& O. Ishymova (SMSRS) translated into Ukrainian.

It has been carried out a descriptive analysis of indicators of the first and second text of the SMSRS in two age groups. The normality of the distribution of variable parameters has been evaluated. According to G. Morgan \& O. Griego (1998), the distribution of variable values in the sample does not differ from the normal one if the absolute values for skewness and kurtosis do not exceed 2.5 times their standard deviations. інших напрямках, окрім читання, нами не проводилося.

Метою статті $\epsilon$ визначення впливу рухових проблем школяра у оволодіння навичками читання; розуміння причини цих проблем за допомогою нейропсихологічних проб; диференціація помилок і визначення ефективних методів корекції. Для досягнення мети було необхідно:

1. Адаптувати україномовну методику діагностики дислексії у дітей (СМОНЧ).

2. Провести нейропсихологічне обстеження дітей.

3. Встановити кореляційні показники нейропсихологічних чинників у руховій сфері дитини і рівня оволодіння навичками читання.

Гіпотеза. Автори статті припускають, що разом з традиційними логопедичними методами корекції дислексії можливо ефективно використовувати нейропсихологічні методики сенсомоторної корекції для дітей з труднощами оволодіння навичками читання після проведення нейропсихологічної діагностики.

\section{Методологія та методи}

Дослідження проведено на основі нейропсихологічного підходу О. Лурії та класичної батареї тестів. Дані методи орієнтовані на потенціал дитини на основі сильних і слабких сторін її розвитку.

Подальша корекція буде створена за методикою М. Бернштейна і його концепції побудови рухів, в якій мовлення та читання читання, виділені як вищі рівні побудови руху.

Вибірка дослідження. У дослідженні взяла участь 61 дитина 3 м. Києва та м. Одеси. Розглянуто розподіл вибірки дослідження за віком: діти 7 років - троє; 8 років - одинадцять; 9 років - сімнадцять; 10 років - шістнадцять; 11 років - дев'ять; 12 років - п'ять.

Сформовано дві, майже рівні за обсягом, вікові групи: 7-9 років $(\mathrm{n}=31)$ та 10-12 років (n = 30). Подальше аналізування проводилося переважно у цих двох групах.

Процедура та інструменти. Було використано батарею нейропсихологічних тестів О. Лурії, адаптовану до дитячого віку Ж. Глозман, методику діагностики дислексії у дітей О. Корнєва і О. Ішимової (СМОНЧ) у перекладі на українську мову. 
Consequently, research findings have been processed using mathematical statistics methods: Pearson correlation coefficient and point-biserial correlation coefficient.

\section{Research results}

The authors have tested the SMSRS Ukrainian version, which identifies indicators that require standardization. The procedure for creating integrated indicators for the SMSRS and determining its construct validity has been conducted. The above has made it possible to correlate the SMSRS indicators with external relevant criteria.

Table 1 contains descriptive statistics for each sub-group under a descriptive analysis of the SMSRS.

The conducted analysis has shown that there are indicators that should be standardized because their distribution significantly differs
Проведено дескриптивне аналізування параметрів першого та другого текстів тесту СМОНЧ у двох вікових групах. Оцінювалась нормальність розподілу змінних параметрів. Згідно Дж. Моргану і О. Грієго (1998) розподіл значень змінної у вибірці не відрізняється від нормального, якщо абсолютні величини асиметрії та ексцесу не перевищують у 2.5 рази свої стандартні похибки. Далі результати дослідження були оброблені за допомогою методів математичної статистики - кореляційний аналіз за Пірсоном та точково-бісеріальних коефіцієнтів кореляції.

\section{Результати дослідження}

Проведено апробацію україномовної версії тесту СМОНЧ, яка виявила показники, що вимагали стандартизації. Проведено процедуру створення інтегральних показників для тесту СМОНЧ та визначення його конструктної валідності. Це

Table 1. Descriptive statistics of the SMSRS parameters (text 1 - 225 words)

Таблиця 1. Описові статистики параметрів тесту СМОНЧ (текст $1-225$ слів)

\begin{tabular}{|c|c|c|c|c|c|c|c|c|}
\hline $\begin{array}{l}\text { Parameter } \\
\text { Параметр }\end{array}$ & $\begin{array}{l}\text { Group, age, } \\
\text { years } \\
\text { Група, вік, } \\
\text { років } \\
\end{array}$ & $\mathbf{M}$ & Mdn & SD & $S$ & SES & $\mathbf{K}$ & SEK \\
\hline \multirow{2}{*}{$\begin{array}{l}\text { Number of words } \\
\text { for } 60 \text { sec. } \\
\text { Кількість слів за } 60 \text { с }\end{array}$} & $7-9$ & 74.130 & 81.000 & 25.216 & -.551 & .421 & -.024 & .821 \\
\hline & $10-12$ & 111.030 & 106.500 & 31.821 & .715 & .427 & .317 & .833 \\
\hline \multirow{2}{*}{$\begin{array}{l}\text { Time of text completion, } \\
\text { sec. } \\
\text { Час виконання всього } \\
\text { тексту, с }\end{array}$} & $7-9$ & 233.550 & 185.000 & 136.723 & $1.920^{*}$ & .421 & $3.387^{*}$ & .821 \\
\hline & $10-12$ & 140.630 & 12.500 & 49.076 & .937 & .427 & .655 & .833 \\
\hline \multirow{2}{*}{$\begin{array}{l}\text { Number of uncorrected } \\
\text { errors } \\
\text { Кількість невиправлених } \\
\text { помилок }\end{array}$} & $7-9$ & 3.350 & 3.000 & 3.104 & $1.239^{*}$ & .421 & 1.454 & .821 \\
\hline & $10-12$ & 1.770 & 1.000 & 2.128 & $1.224^{*}$ & .427 & .516 & .833 \\
\hline \multirow{2}{*}{$\begin{array}{l}\text { Reading assessment } \\
\text { techniques } \\
\text { Оцінка способу читання }\end{array}$} & $7-9$ & 3.350 & 4.000 & .798 & $-1.173^{*}$ & .421 & 1.077 & .821 \\
\hline & $10-12$ & 3.670 & 4.000 & .479 & -.745 & .427 & -1.554 & .833 \\
\hline \multirow{2}{*}{$\begin{array}{l}\text { Reading comprehension } \\
\text { Розуміння прочитаного }\end{array}$} & $7-9$ & 2.839 & 3.000 & .934 & -.183 & .421 & -.965 & .821 \\
\hline & $10-12$ & 3.167 & 3.000 & .834 & -.715 & .427 & -.083 & .833 \\
\hline
\end{tabular}

Note: * skewness and kurtosis of indicators, the distribution of which significantly differs from normal one under the G. Morgan \& 0. Griego criterion. Descriptive statistics: arithmetic mean (M), median (Mdn), standard deviation (SD), skewness (S) and standard error of skewness (SES), kurtosis (K) and standard error of kurtosis (SEK).

Примітка: знаком * позначені значення асиметрії та ексцесу тих показників, розподіл яких за критерієм Дж. Моргану і О. Грієго суттєво відрізняється від нормального. Описова статистика: середнє арифметичне значення (M), медіана (Mdn), стандартне відхилення (SD), асиметрія (S) та стандартна похибка асиметрії (SES), ексцес (K) та стандартна похибка ексцесу (SEK).

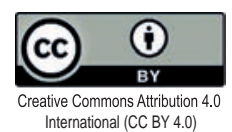


from a normal one. In text 1 , it concerns the time of text completion, sec; the number of uncorrected errors; reading assessment techniques.

In text 2, there are indicators that should be standardized because their distribution significantly differs from normal one: the time of text completion, reading assessment techniques.

Taking into account the above, standard scores (standard five-score system) have been established for the SMSRS partial indicators (table 3).

Further, the procedure for creating the SMSRS integral indicators and estimating its construct validity has been carried out. The procedure has followed the study sample without reference to separation into age groups using confirmatory factor analysis (CFA).

Figure 1 represents a path diagram describing CFA results to produce an integral indicator under the first SMSRS text.

SMSRS for text 1 shows a high compliance of empirical data. This allows suggesting onedimensionality of the construct assessed by the text. дозволило співвіднести показники тесту СМОНЧ з зовнішніми релевантними критеріями.

У таблиці 1 наведено описові статистики для кожної підгрупи при дескриптивному аналізуванні тесту СМОНЧ.

Проведене аналізування показало, що $€$ показники, що потребують стандартизації, адже їхній розподіл суттєво відрізняється від нормального. Для тексту 1: час виконання всього тексту, с; кількість невиправлених помилок; оцінка способу читання.

Для тексту 2 - це показники, які потребують стандартизації, адже їхній розподіл суттєво відрізняється від нормального: час виконання всього тексту; оцінка способу читання.

Виходячи 3 цього, було визначено стандартні бали (стандартні п'ятірки) для часткових показників тесту СМОНЧ (таблиця 3).

Далі було проведено процедуру створення інтегральних показників для тесту СМОНЧ та визначення його конструктної валідності. Ця процедура проводилась за вибіркою

Table 2. Descriptive statistics of the SMSRS parameters (text 2 - 224 words)

Таблиця 2. Описові статистики параметрів тесту СМОНЧ (текст 2 - 224 слова)

\begin{tabular}{|c|c|c|c|c|c|c|c|c|}
\hline $\begin{array}{l}\text { Parameter } \\
\text { Параметр }\end{array}$ & $\begin{array}{l}\text { Group, } \\
\text { age, years } \\
\text { Група, } \\
\text { вік, років }\end{array}$ & $\mathbf{M}$ & Mdn & SD & $\mathbf{S}$ & SES & $\mathbf{K}$ & SEK \\
\hline \multirow{2}{*}{$\begin{array}{l}\text { Number of words per } 60 \text { sec. } \\
\text { Кількість слів за } 60 \text { с }\end{array}$} & $7-9$ & 68.900 & 71.000 & 27.492 & -.047 & .421 & -.940 & .821 \\
\hline & $10-12$ & 100.470 & 100.500 & 29.144 & .122 & .427 & -.712 & .833 \\
\hline \multirow{2}{*}{$\begin{array}{l}\text { Time of text completion, sec. } \\
\text { Час виконання всього тексту, с }\end{array}$} & $7-9$ & 312.260 & 241.000 & 202.554 & $1.347^{*}$ & .421 & 1.104 & .821 \\
\hline & $10-12$ & 158.070 & 143.500 & 62.310 & 1.409* & .427 & $2.372^{*}$ & .833 \\
\hline \multirow{2}{*}{$\begin{array}{l}\text { Number of uncorrected errors } \\
\text { Кількість невиправлених } \\
\text { помилок }\end{array}$} & $7-9$ & 5.030 & 4.000 & 3.737 & .755 & .421 & -.094 & .821 \\
\hline & $10-12$ & 2.600 & 3.000 & 2.127 & .289 & .427 & -1.029 & .833 \\
\hline \multirow{2}{*}{$\begin{array}{l}\text { Reading assessment } \\
\text { techniques } \\
\text { Оцінка способу читання }\end{array}$} & $7-9$ & 3.230 & 3.000 & .805 & -.446 & .421 & -1.298 & .821 \\
\hline & $10-12$ & 3.670 & 4.000 & .547 & $-1.407^{*}$ & .427 & 1.201 & .833 \\
\hline \multirow{2}{*}{$\begin{array}{l}\text { Reading comprehension } \\
\text { Розуміння прочитаного }\end{array}$} & $7-9$ & 2.032 & 2.000 & .836 & .303 & .421 & -.639 & .821 \\
\hline & $10-12$ & 2.667 & 3.000 & .844 & -.382 & .427 & -.200 & .833 \\
\hline
\end{tabular}

Note: * skewness and kurtosis of the indicators, the distribution of which significantly differs from normal one under the G. Morgan \& O. Griego criterion. Descriptive statistics: arithmetic mean (M), median (Mdn), standard deviation (SD), skewness (S) and standard error of skewness (SES), kurtosis (K) and standard error of kurtosis (SEK).

Примітка: знаком * позначені значення асиметрії та ексцесу тих показників, розподіл яких за критерієм Дж. Моргану і О. Грієго суттєво відрізняється від нормального. Описова статистика: середнє арифметичне значення (M), медіана (Mdn), стандартне відхилення (SD), асиметрія (S) та стандартна похибка асиметрії (SES), ексцес (K) та стандартна похибка ексцесу (SEK).

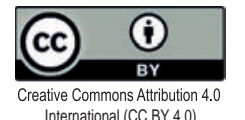




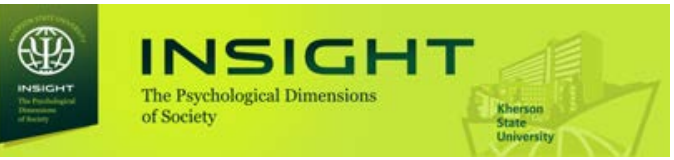

\section{Kiparenko Olena, Kremenchutska Margaryta}

Table 3. Value of standard scores (standard five-score system) for the SMSRS indicators

Таблиця 3. Значення стандартних балів (стандартні п’ятірки) для показників тесту СМОНЧ

\begin{tabular}{|c|c|c|c|c|c|c|c|c|}
\hline \multirow{3}{*}{$\begin{array}{l}\text { Parameter } \\
\text { Параметр }\end{array}$} & \multicolumn{8}{|c|}{$\begin{array}{l}\text { Score threshold } \\
\text { Граничні значення балів }\end{array}$} \\
\hline & \multicolumn{4}{|c|}{ 7-9 years } & \multicolumn{4}{|c|}{$10-12$ years } \\
\hline & $\begin{array}{c}0 / 1 \\
\text { sсоre/ } \\
\text { бали }\end{array}$ & $\begin{array}{c}1 / 2 \\
\text { scores/ } \\
\text { бали }\end{array}$ & $\begin{array}{c}2 / 3 \\
\text { scores/ } \\
\text { бали }\end{array}$ & $\begin{array}{c}3 / 4 \\
\text { scores/ } \\
\text { бали }\end{array}$ & $\begin{array}{c}0 / 1 \\
\text { score/ } \\
\text { бали }\end{array}$ & $\begin{array}{c}1 / 2 \\
\text { scores/ } \\
\text { бали } \\
\end{array}$ & $\begin{array}{c}2 / 3 \\
\text { scores/ } \\
\text { бали }\end{array}$ & $\begin{array}{c}3 / 4 \\
\text { scores/ } \\
\text { бали }\end{array}$ \\
\hline \multicolumn{9}{|c|}{$\begin{array}{c}\text { Text } 1 \\
\text { Tекст } 1 \\
\end{array}$} \\
\hline $\begin{array}{l}\text { Number of words } \\
\text { per } 60 \text { sec. } \\
\text { Кількість слів за } 60 \text { с }\end{array}$ & 21.72 & 57.00 & 88.51 & 110.72 & 66.85 & 89.00 & 126.31 & 176.01 \\
\hline $\begin{array}{l}\text { Time of text } \\
\text { completion, sec. } \\
\text { Час виконання } \\
\text { всього тексту, с }\end{array}$ & 119.14 & 164.59 & 245.64 & 584.86 & 78.14 & 110.56 & 160.31 & 234.58 \\
\hline $\begin{array}{l}\text { Number of } \\
\text { uncorrected errors } \\
\text { Кількість помилок, } \\
\text { які не виправлені }\end{array}$ & .00 & 1.00 & 4.00 & 10.59 & .00 & .00 & 2.00 & 6.00 \\
\hline \multicolumn{9}{|c|}{$\begin{array}{c}\text { Text } 2 \\
\text { Текст } 2 \\
\end{array}$} \\
\hline $\begin{array}{l}\text { Number of words } \\
\text { for } 60 \text { sec. } \\
\text { Кількість слів } \\
\text { за } 1 \text { хвилину }\end{array}$ & 23.34 & 50.74 & 85.51 & 110.00 & 50.13 & 79.56 & 116.24 & 144.65 \\
\hline $\begin{array}{l}\text { Time of text } \\
\text { completion, sec. } \\
\text { Час виконання } \\
\text { всього тексту, с }\end{array}$ & 127.55 & 168.00 & 309.83 & 706.79 & 86.42 & 125.00 & 173.73 & 297.33 \\
\hline $\begin{array}{l}\text { Number of } \\
\text { uncorrected errors } \\
\text { Кількість } \\
\text { невиправлених } \\
\text { помилок }\end{array}$ & .00 & 2.87 & 7.00 & 12.00 & .00 & 1.00 & 4.00 & 6.00 \\
\hline
\end{tabular}

Figure 2 conveys a path diagram describing CFA results to produce an integral indicator under the second SMSRS text.

It is worth noting that the standardized ratio for text 2 is higher than the absolute value of test 1 . This may mean that this test is not one-way, and its results should be analyzed in both quantitative and qualitative terms.

Analysis results of the construct validity using Cronbach's alpha $(\alpha)$ indicate the internal consistency of the tests (threshold level for achievement tests $\alpha=.700$ ) and justify the conclusions obtained by CFA. Thus, coefficients for the SMSRS 1 are as follows: $\alpha=.370-$ for the group of 7-9 years; $\alpha=.658-$ for the group дослідження без врахування розподілу на вікові групи за допомогою процедури конфірматорного факторного аналізу.

На рисунку 1 подано шляхову діаграму, яка описує результати конфірматорного аналізу для створення інтегрального показника за першим текстом СМОНЧ.

Тест СМОНЧ варіант для тексту 1 показав високу відповідність емпіричних даних. Це дозволяє говорити про одномірність конструкту, що вимірюється цим тестом.

На рисунку 2 подано шляхову діаграма, яка описує результати конфірматорного аналізу для створення інтегрального показника за другим текстом СМОНЧ.

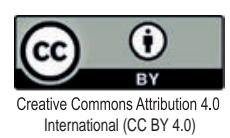




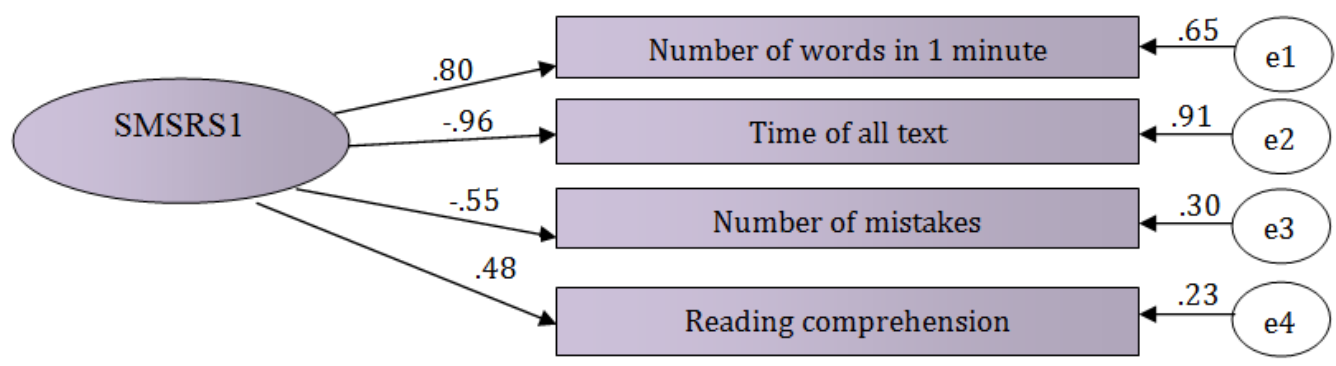

Fig. 1. A path diagram representing CFA results for an integral indicator under the SMSRS text (Text 1 ) Рис. 1. Шляхова діаграма, що репрезентує результати конфірматорного аналізу для інтегрального показника тесту СМОНЧ (Текст 1).

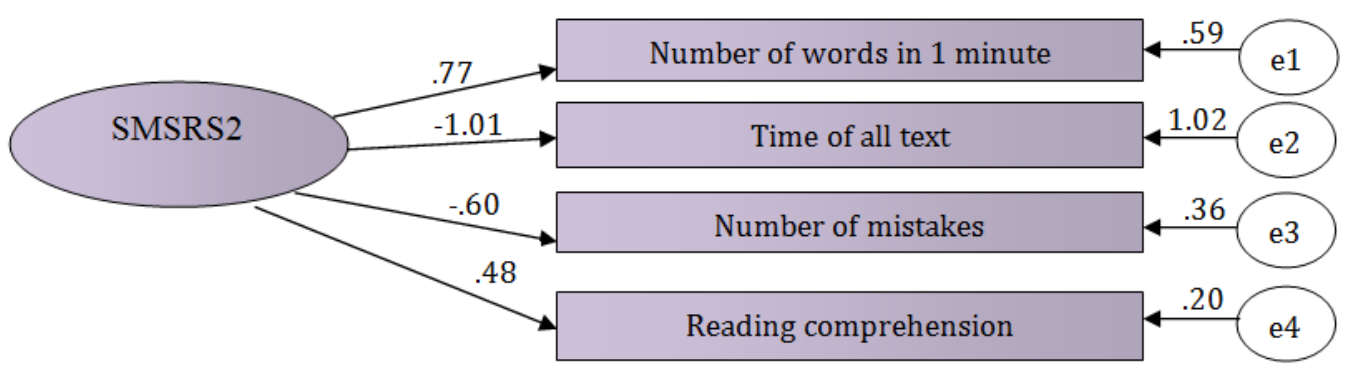

Fig. 2. A path diagram representing CFA results for an integral indicator under the SMSRS text (Text 2) Рис. 2. Шляхова діаграма, що репрезентує результати конфірматорного аналізу для інтегрального показника тесту СМОНЧ (Текст 2).

of 10-12 years; for the SMSRS 2: $\alpha=.295-$ for the group of 7-9 years; $\alpha=.577-$ for the group of 10-12 years.

The correlation of SMSRS indicators with external relevant criteria has been implemented through calculating Pearson correlation coefficients and point-biserial correlation coefficients in two age groups.

Indicators of 0 . Luria's neuropsychological test have been used as external relevant criteria (J. Glozman's adaptation).

The results show statistically significant correlation coefficients of most indicators in motor tests for children aged 7-9 years. The most significant coefficients at the $\mathrm{p}<.01$ level are as follows: finger praxis (right hand) $(r=.753$; $\mathrm{p}=.000$ ), one handed (Head test), right hand ( $\mathrm{r}=.502 ; \mathrm{p}=.004)$, one handed (Head test), left hand ( $\mathrm{r}=.467 ; \mathrm{p}=.008)$, dynamic praxis, right hand $(\mathrm{r}=.532 ; \mathrm{p}=.002)$, graphic test for dynamic praxis $(\mathrm{r}=.621 ; \mathrm{p}=.000)$. The most significant coefficient
Слід зазначити, що стандартизований коефіцієнт тексту для тексту 2 був більшим за абсолютне значення тесту 1 . Це може означати, що даний тест не є однофакторним і його результати треба аналізувати як в кількісному, так і в якісному вимірах.

Результати аналізування конструктної валідності за допомогою коефіцієнта $\alpha$ Кронбаха, свідчать про внутрішню узгодженість тестів (граничний рівень для тестів досягнень $\alpha=.700$ ) і підтверджують висновки, отримані за допомогою конфірматорного факторного аналізу. Так ці коефіцієнти дорівнювали відповідно для СМОНЧ1: $\alpha=.370$ - для групи 7-9 років; $\alpha=.658$ - для групи 10-12 років. Для СМОНЧ2: $\alpha=.295$ - для групи 7-9 років; $\alpha=.577$ - для групи 10-12 років.

Співвіднесення показників тесту СМОНЧ із зовнішніми релевантними критеріями відбувалось шляхом розрахунку коефіцієнтів кореляції Пірсона та точечно-бісеріальних 
at the $\mathrm{p}<.05$ level is reciprocal movements of hands ( $\mathrm{r}=.414 ; \mathrm{p}=.021)$.

J. Glozman's technique allows specifying essential errors in performing diagnostic tests коефіцієнтів кореляції у двох вікових групах.

У якості зовнішніх релевантних критеріїв виступали показники нейропсихологічних тестів О. Лурії (адаптація Ж. Глозман).

Table 4. Correlations of the parameter "Number of words per 60 sec." under the SMSRS (Text 1) with relevant criteria Таблиця 4. Кореляції показника “кількість слів за 60 с" тесту СМОНЧ (Текст 1) з релевантними критеріями

\begin{tabular}{|c|c|c|c|c|}
\hline \multirow{3}{*}{$\begin{array}{c}\text { Relevant criteria } \\
\text { Релевантні критерії }\end{array}$} & \multicolumn{4}{|c|}{$\begin{array}{l}\text { Age group, years } \\
\text { Вікова група, років }\end{array}$} \\
\hline & \multicolumn{2}{|c|}{$7-9$} & \multicolumn{2}{|c|}{$10-12$} \\
\hline & $\mathbf{r}\left(\mathbf{r}_{\mathrm{pb}}\right)$ & $\mathbf{P}$ & $r\left(r_{p b}\right)$ & $\mathbf{P}$ \\
\hline $\begin{array}{l}\text { Finger praxis (right hand) } \\
\text { Праксис пози пальців (права рука) }\end{array}$ & $.753^{* *}$ & .000 & .176 & .353 \\
\hline $\begin{array}{l}\text { One handed (Head test), right hand } \\
\text { Одноручні (поза Хеда), права рука }\end{array}$ & $.502^{* *}$ & .004 & $.382^{*}$ & .037 \\
\hline $\begin{array}{l}\text { One handed (Head test), left hand } \\
\text { Одноручні (поза Хеда), ліва рука }\end{array}$ & $.467^{* *}$ & .008 & .228 & .225 \\
\hline $\begin{array}{l}\text { Dynamic praxis, right hand } \\
\text { Динамічний праксис права рука }\end{array}$ & $.532^{* *}$ & .002 & .309 & .096 \\
\hline $\begin{array}{l}\text { Graphic test for dynamic praxis } \\
\text { Графічна проба на динамічний праксис }\end{array}$ & $.621^{* *}$ & .000 & $.368^{*}$ & .045 \\
\hline $\begin{array}{l}\text { Reciprocal coordination } \\
\text { Реципрокна координація }\end{array}$ & $.414^{*}$ & .021 & .101 & .597 \\
\hline $\begin{array}{l}\text { Oral praxis } \\
\text { Оральний праксис }\end{array}$ & .091 & .626 & $.405^{*}$ & .027 \\
\hline \multicolumn{5}{|c|}{$\begin{array}{c}\text { Fixed errors: } \\
\text { Зафіксовані помилки: }\end{array}$} \\
\hline $\begin{array}{l}\text { Difficulties of getting outside of a task } \\
\text { Труднощі виходження у завдання }\end{array}$ & $-.476^{* *}$ & .007 & -.249 & .185 \\
\hline $\begin{array}{l}\text { Impulsivity of movement tests } \\
\text { Імпульсивність у рухових пробах }\end{array}$ & $-.635^{* *}$ & .000 & -.072 & .706 \\
\hline $\begin{array}{l}\text { Stereotypies in dynamic praxis } \\
\text { Стереотипії у динамічному праксисі }\end{array}$ & $-.391 *$ & .030 & -.116 & .540 \\
\hline $\begin{array}{l}\text { Inactivity } \\
\text { Інертність }\end{array}$ & $-.371^{*}$ & .040 & -.164 & .386 \\
\hline $\begin{array}{l}\text { Non-automated (fragmentary) movements } \\
\text { Неавтоматизація (уривчастість) рухів }\end{array}$ & $-.543^{* *}$ & .002 & .142 & .453 \\
\hline $\begin{array}{l}\text { Kinesthetic difficulties } \\
\text { Кінестетичні труднощі }\end{array}$ & $-.373^{*}$ & .038 & -.165 & .383 \\
\hline $\begin{array}{l}\text { Sequence or symmetrical execution of movements } \\
\text { Черговість або симетричне виконання рухів }\end{array}$ & $-.360^{*}$ & .047 & -.093 & .623 \\
\hline $\begin{array}{l}\text { Retardation of one hand in reciprocal coordination } \\
\text { Відставання однієї руки у реципрокній координації }\end{array}$ & $-.496^{* *}$ & .005 & .307 & .099 \\
\hline $\begin{array}{l}\text { Systemic perseverations } \\
\text { Системні персеверації }\end{array}$ & $-.526^{* *}$ & .002 & -.251 & .181 \\
\hline $\begin{array}{l}\text { General motor awkwardness } \\
\text { Загальна моторна незграбність }\end{array}$ & $-.421^{*}$ & .018 & -.114 & .549 \\
\hline
\end{tabular}

Note: statistically significant correlation coefficients: ${ }^{*}-\mathrm{p}<.05$; $^{* *}-\mathrm{p}<.01$; $^{* *}-\mathrm{p}<.001$.

Примітка: надано статистично значущі коефіцієнти кореляції:* - на рівні $\mathrm{p}<.05$; ** - на рівні р <.01; *** - на рівні $\mathrm{p}<.001$. 
that gives an opportunity to develop the most effective inventory route for work with a child. According to performance figures, there are also errors in movement tests, which affect the mastering of reading skills. The most significant coefficients at the $\mathrm{p}<.01$ level are as follows: difficulties of getting outside a task ( $\mathrm{r}=-.476 ; \mathrm{p}=.007$ ), impulsivity of movement tests ( $\mathrm{r}=-.635 ; \mathrm{p}=.000$ ), non-automated (fragmentary) movements $(r=-.543 ; p=.021)$, retardation of one hand in reciprocal coordination $(\mathrm{r}=-.496 ; \mathrm{p}=.005)$, systemic perseverations $(\mathrm{r}=-.526 ; \mathrm{p}=.002)$.
Результати для дітей 7-9 років показують статистично значущі коефіцієнти кореляції більшості показників у рухових пробах. Найбільш значущими коефіцієнтами на рівні $\mathrm{p}<.01 \epsilon$ праксис пози пальців правої руки ( $\mathrm{r}=.753 ; \mathrm{p}=.000)$, одноручна поза Хеда правою рукою ( $\mathrm{r}=.502 ; \mathrm{p}=.004)$, одноручна поза Хеда лівою рукою $(\mathrm{r}=.467$; $\mathrm{p}=.008)$, динамічний праксис правою рукою ( $\mathrm{r}=.532 ; \mathrm{p}=.002)$, графічна проба на динамічний праксис (r=.621; p=.000). Найбільш значущим коефіцієнтом на рівні $\mathrm{p}<.05 €$ реципрокна координація рук (r=.414; $\mathrm{p}=.021)$.

Table 5. Correlations of the parameter "Number of words per 60 sec." under the SMSRS (Text 2) with relevant criteria Таблиця 5. Кореляції показника “кількість слів за 60 c" тесту СМОНЧ (Текст 2) з релевантними критеріями

\begin{tabular}{|c|c|c|c|c|}
\hline \multirow{3}{*}{$\begin{array}{c}\text { Relevant criteria } \\
\text { Релевантні критерї̈ }\end{array}$} & \multicolumn{4}{|c|}{$\begin{array}{l}\text { Age group, years } \\
\text { Вікова група, років }\end{array}$} \\
\hline & \multicolumn{2}{|c|}{$7-9$} & \multicolumn{2}{|c|}{ 10-12 } \\
\hline & $\mathbf{r}\left(\mathbf{r}_{\mathrm{pb}}\right)$ & $\mathbf{P}$ & $r\left(r_{p b}\right)$ & $\mathbf{P}$ \\
\hline $\begin{array}{l}\text { Finger praxis (right hand) } \\
\text { Праксис пози пальців (права рука) }\end{array}$ & $.699 * *$ & .000 & .176 & .352 \\
\hline $\begin{array}{l}\text { One handed Head test, right hand } \\
\text { Одноручні (поза Хеда), права рука }\end{array}$ & $.422^{*}$ & .018 & $.425^{*}$ & .019 \\
\hline $\begin{array}{l}\text { One handed Head test, left hand } \\
\text { Одноручні (поза Хеда), ліва рука }\end{array}$ & $.358^{*}$ & .048 & .291 & .119 \\
\hline $\begin{array}{l}\text { Dynamic praxis, right hand } \\
\text { Динамічний праксис права рука }\end{array}$ & $.498^{* *}$ & .004 & .359 & .052 \\
\hline $\begin{array}{l}\text { Graphic test for dynamic praxis } \\
\text { Графічна проба на динамічний праксис }\end{array}$ & $.543^{* *}$ & .002 & 360 & .051 \\
\hline $\begin{array}{l}\text { Reciprocal coordination } \\
\text { Оральний праксис }\end{array}$ & .073 & .695 & $.444^{*}$ & .014 \\
\hline \multicolumn{5}{|c|}{$\begin{array}{c}\text { Fixed errors: } \\
\text { Зафіксовані помилки: }\end{array}$} \\
\hline $\begin{array}{l}\text { Difficulties of getting outside of a task } \\
\text { Труднощі виходження у завдання }\end{array}$ & $-.459 * *$ & .009 & -.260 & .165 \\
\hline $\begin{array}{l}\text { Impulsivity of movement tests } \\
\text { Імпульсивність у рухових пробах }\end{array}$ & $-.556^{* *}$ & .001 & -.035 & .853 \\
\hline $\begin{array}{l}\text { Stereotypies in dynamic praxis } \\
\text { Неавтоматизація (уривчастість) рухів }\end{array}$ & $-.579 * *$ & .001 & .127 & .504 \\
\hline $\begin{array}{l}\text { Inactivity } \\
\text { Черговість або симетричне виконання рухів }\end{array}$ & $-.361^{*}$ & .046 & .008 & .966 \\
\hline $\begin{array}{l}\text { Non-automated (fragmentary) movements } \\
\text { Відставання однієї руки у реципрокній координації }\end{array}$ & $-.419^{*}$ & .019 & .175 & .355 \\
\hline $\begin{array}{l}\text { Kinesthetic difficulties } \\
\text { Наявність синкінезій }\end{array}$ & -.309 & .090 & $-.414^{*}$ & .023 \\
\hline $\begin{array}{l}\text { Sequence or symmetrical execution of movements } \\
\text { Системні персеверації }\end{array}$ & $-.456^{* *}$ & .010 & -.304 & .102 \\
\hline
\end{tabular}

Note: statistically significant correlation coefficients: ${ }^{*}-\mathrm{p}<.05$; $^{* *}-\mathrm{p}<.01$; $^{* *}-\mathrm{p}<.001$.

Примітка: надано статистично значущі коефіцієнти кореляції: * - на рівні $\mathrm{p}<.05$; ** - на рівні $\mathrm{p}<.01$; *** - на рівні $\mathrm{p}<.001$. 


\section{Kiparenko Olena, Kremenchutska Margaryta}

Children aged 10-12 years have a more organized and focused functioning of the motor system and a small number of errors when performing tests.

The second text is more complicated for children's reading. The mostsignificant coefficients at the $\mathrm{p}<.01$ level are: finger praxis (right hand) $(\mathrm{r}=.699 ; \mathrm{p}=.000)$, dynamic praxis, right hand $(\mathrm{r}=0.498 ; \mathrm{p}=.004)$, graphic test for dynamic praxis $(r=.554 ; p=.002)$. The most significant coefficients at the $\mathrm{p}<.05$ level are one handed Head test, right hand $(\mathrm{r}=.422 ; \mathrm{p}=.018)$, one handed Head test, left hand $(\mathrm{r}=.358 ; \mathrm{p}=.048)$.

Among performance defects, there are observed the most significant coefficients at the $\mathrm{p}<.01$ level, namely: difficulties of getting outside a task ( $\mathrm{r}=-.459 ; \mathrm{p}=.009$ ), the impulsivity of movement tests $(\mathrm{r}=-.556 ; \mathrm{p}=.001)$, non-automated (fragmentary) movements $(\mathrm{r}=-.579, \mathrm{p}=.001)$, systemic perseverations $(r=-.456 ; p=.010)$.

The most significant coefficients at the $\mathrm{p}<.05$ level are sequence or symmetrical execution of movements ( $\mathrm{r}=-.361 ; \mathrm{p}=.046)$, retardation of one hand in reciprocal coordination of hands $(\mathrm{r}=-.419 ; \mathrm{p}=.019)$.

Children aged 10-12 years have a small number of errors in reading a more complicated text. The presence of synkineses $(r=-.414 ; p=.023)$ in this age draws attention.

\section{Discussion}

The data obtained give us additional information about the causes of school difficulties, in particular, reading. A child needs basic background support of some components to be involved in classroom learning, e.g., the ability to maintain a working posture during the lesson will improve information perception and mental activity.

According to the obtained results, it is confirmed a significant influence of the immaturity of neuropsychological factors (kinetic, kinesthetic, interhemispheric interaction, neurodynamic, etc.) on reading technique difficulties in children aged 7-9 years.

The same factors are less noticeable and scarcely affect reading skills in children aged 10-12 years. It is stated that reading ability and reading comprehension lay the groundwork for the successful mastering of the school curriculum. Therefore, it is of prime importance
Методика Ж. Глозман дозволяє виділити важливі помилки при виконанні діагностичних проб, що дає можливість у подальшому скласти максимально правильний корекційний маршрут для роботи з дитиною. У рухових пробах за результатами роботи також виділені помилки, які впливають на труднощі оволодіння навичками читання. Найбільш значущими коефіцієнтами на рівні $\mathrm{p}<.01 \epsilon$ труднощі входження в завдання ( $\mathrm{r}=-.476$; $\mathrm{p}=.007)$, імпульсивність у рухових пробах ( $\mathrm{r}=-.635$; $\mathrm{p}=.000$ ), неавтоматизація (уривчастість) рухів ( $\mathrm{r}=-.543 ; \mathrm{p}=.021)$, відставання однієї руки у реципрокній координації ( $r=-.496 ; p=.005)$, системні персеверації (r= -.526; p=.002). Найбільш значущими коефіцієнтами на рівні $\mathrm{p}<.05 €$ стереотипії в динамічному праксисі ( $\mathrm{r}=-.391 ; \mathrm{p}=.030)$, інертність ( $\mathrm{r}=-.371 ; \mathrm{p}=.040)$, кінестетичні труднощі ( $\mathrm{r}=-.373 ; \mathrm{p}=.038)$, черговість або симетричне виконання рухів ( $\mathrm{r}=-.360 ; \mathrm{p}=.047)$, загальна моторна незграбність ( $\mathrm{r}=-.421 ; \mathrm{p}=.018)$.

Діти 10-12 років мають більш організовану цілеспрямовану роботу рухової системи і вони показують невелику кількість помилок при виконанні проб.

Другий текст є складнішим для читання для дітей. Найбільш значущими коефіцієнтами на рівні $\mathrm{p}<.01 €$ праксис пози пальців правої руки ( $\mathrm{r}=.699 ; \mathrm{p}=.000)$, динамічний праксис правою рукою ( $\mathrm{r}=0.498 ; \mathrm{p}=.004)$, графічна проба на динамічний праксис ( $\mathrm{r}=.554 ; \mathrm{p}=.002)$. Найбільш значущими коефіцієнтам на рівні $\mathrm{p}<.05 \epsilon$ одноручна поза Хеда правою рукою $(\mathrm{r}=.422 ; \mathrm{p}=.018)$, одноручна поза Хеда лівою рукою $(\mathrm{r}=.358 ; \mathrm{p}=.048)$.

Серед дефектів виконання бачимо найбільш значущі коефіцієнти на рівні $\mathrm{p}<.01$ такі, як: труднощі входження у завдання (r= -.459; $\mathrm{p}=.009)$, імпульсивність у рухових пробах ( $\mathrm{r}=-.556 ; \mathrm{p}=.001)$, неавтоматизація (уривчастість) рухів ( $\mathrm{r}=-.579$, $\mathrm{p}=.001)$, системні персеверації ( $\mathrm{r}=-.456 ; \mathrm{p}=.010)$.

Найбільш значущими коефіцієнтами на рівні $\mathrm{p}<.05 €$ черговість або симетричне виконання рухів ( $\mathrm{r}=-.361 ; \mathrm{p}=.046)$, відставання однієї руки в реципрокній координації рук $(\mathrm{r}=-.419 ; \mathrm{p}=.019)$.

У дітей 10-12 років вплив на техніку читання більш складного тексту має незначна кількість помилок. Викликає увагу наявність синкінезій (r= -.414; p=.023) у даному віці. 
Assessment of the impact of motor development on adaptation to learning

in primary school because a child learns basic knowledge (problem solving, answering questions about a text, etc.).

The results show significant regulatory errors in younger students (impulsivity, perseverations). The intervention program requires exercises to improve regulation at the level of the body and motor act.

In addition, it has been found that there are significant difficulties at the level of the first functional block of the brain, neurodynamic regulation: it refers to the challenge of getting out a task and synkineses. The latter attract special attention because they are observed in children aged 10-12 years - they should not be. This may indicate a severe lack of energy in the focused work of a student. Insufficient interhemispheric interaction has been marked at the level of motor act in both groups of students.

It is conceivable that motor correction will most likely not help a child with dyslexia, and additional methods are needed. For example, such a factor as egocentric speech in a younger student is directly associated with the development of further thinking of the child, and it will essentially complicate the adequacy of reading comprehension. In younger students, the structure of speech has already been reformed, and egocentric speech should switch to inner one (Radul, 2019). However, if one finds errors in the diagnosis of purposeful movements, works them out using the intervention program, the background lower levels of movement construction will create a strong foundation for the child's mastering reading.

In terms of the neuropsychological approach, difficulties of regulation, neurological dynamics, and interhemispheric interaction are the factors that should be involved at the initial stage for successful development of a child. The correction begins at the motor level and gradually moves into the intellectual, cognitive sphere.

\section{Conclusions}

Research findings allow holding that reading, as a specific form of the higher mental function of speech, is a rather multifactorial process. Nowadays, classes for kids aimed at driving speech activity through movement are successful

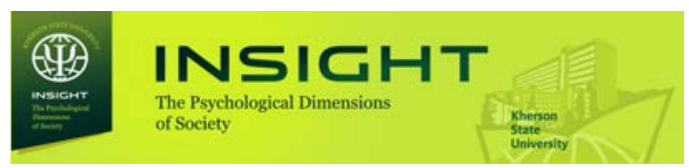

\section{Дискусія}

Отримані дані дають нам додаткову інформацію стосовно причин шкільних труднощів, зокрема з читання. Для того, щоб вчитися на уроці у школі дитині необхідна базова фонова підтримка певних компонентів, наприклад: можливість утримування робочої пози під час уроку, покращить сприйняття матеріалу і розумову діяльність.

За отриманими результатами, констатуємо значний вплив несформованості нейропсихологічних чинників (кінетичний, кінестетичний, міжпівкульної взаємодії, нейродинамічний та ін.) на труднощі техніки читання у дітей 7-9 років.

У дітей 10-12 років ці чинники менш виражені і практично не впливають на навички читання. Стверджуємо, що вміння читати і розуміти прочитане закладає основу успішного опанування шкільної програми в цілому. Тому в початкових класах це особливо важливо, тому що дитина навчається базових знань (рішення задач, відповіді на питання щодо прочитаного тексту і т. п.).

Результати показують значні регуляторні помилки у молодших школярів (імпульсивність, персеверації). У корекційній програмі необхідні вправи для поліпшення регуляції на рівні тіла, на рівні рухового акту.

Також, з'ясовано, що є значні труднощі на рівні першого функціонального блоку головного мозку, нейродинамічна регуляція - це труднощі входження в завдання і синкінезії. Останні привертають особливу увагу, бо вони спостерігаються у дітей 10-12 років, за нормою їх бути не має. Це може говорити про значну нестачу енергії при цілеспрямованій роботі школяра. Констатовано недостатню міжпівкульну взаємодію вже на рівні рухового акту в обох групах школярів.

Ми розуміємо, що швидше за все дитині 3 дислексією не завжди допоможе тільки рухова корекція, потрібні додаткові методи. Такий чинник, наприклад, як егоцентричне мовлення у молодшого школяра безпосередньо пов'язаний з розвитком подальшого мислення дитини і це значно ускладнить адекватність сприйняття прочитаного. У молодших школярів структура мовлення вже перебудована i, в нормі егоцентрична мова вже має 
enough. Although some time ago, only medical specialists and speech therapists dealt with this issue. In particular, praxis plays a significant role in the formation and development of reading skills in younger students.

Neuropsychological diagnostics has made it possible to define a level of the student's difficulties in the motor sphere under concurrent difficulties of mastering reading skills. The obtained results state that there are not only direct ways to help a child in learning. Drawing up an intervention program based on the formation of the correct motor patterns can be a constructive basis for successful work.

Summing up, a child encounters the emergence of more highly organized semantic and grammatical forms in reading, and thus the control of speech turns from the subject level to a higher, and a particular motive for action appears.

\section{References:}

Alice, van de Walle de Ghelcke, A., Skoura, X., Edwards, M.G., Quercia, P. and Papaxanthis, C. (2021). Action representation deficits in adolescents with developmental dyslexia. J. Neuropsychology, 15, 215-234. https://doi.org/10.1111/jnp.12220

Azorín, E. I., Lobo, P. M., Vergara-Moragues, E., \& Calvo, A. (2018). Neuropsychological program of english learning for students with dyslexia. Electronic Journal of Research in Education Psychology, 16(45), 417. DOI: 10.25115 /ejrep.v16i45.2100

Glozman, J., \& Nemeth, D. G. (2020). The contributions of Luria and Reitan to developmental neuropsychology and to the understanding of neuropsychologically compromised children. Evaluation and Treatment of Neuropsychologically Compromised Children, 1-26. DOI: 10.1016/b978-0-12819545-1.00001-1

González-Valenzuela, M., \& Martín-Ruiz, I. (2021). Neuropsychological Perspective on Dyslexia. Learning Disabilities [Working Title]. DOI: 10.5772/ intechopen.99386

Kiparenko, O. (2020). Sensorna intehratsiia yak metod korektsii rozladiv u ditei [Sensory integration as a method of correction of disorders in children]. Zbirnyk naukovykh prats "Problemy suchasnoi psykholohii" - Collection of scientific works "Problems of modern psychology", (49), 2020. C. 152-176. https://doi.org/10.32626/222 7-6246.202049.152-176

Maelle Biotteau, Jean-Michel Albaret, Sandrine Lelong \& Yves Chaix (2017). Neuropsychological status of French children with developmental dyslexia перейти у внутрішню (Радул, 2019). Але, якщо виявити у діагностиці помилки при цілеспрямованих рухах, відпрацювати їх далі в корекційній програмі, то фонові нижні рівні побудови руху дадуть потужний фундамент дитині для оволодіння читанням.

У нейропсихологічному підході труднощі регуляції, і нейродинаміка, і міжпівкульна взаємодія - це ті чинники, з якими необхідно починати роботу для успішного розвитку дитини. Корекція починається на руховому рівні і поступово переходить в інтелектуальну, когнітивну сферу.

\section{Висновки}

Отримані дані дають підстави стверджувати, що читання, як особлива форма вищої психічної функції мовлення, $\epsilon$ досить багаточинниковим процесом. Сьогодні досить успішно проходять заняття для малюків із запуску мовлення через рух, хоча ще якийсь час назад цим питанням займалися тільки медичні фахівці та логопеди. Зокрема, праксис має значущу роль у формуванні і розвитку навичок читання у молодших школярів.

Проведення нейропсихологічної діагностики дозволило визначити рівень труднощів школяра у руховій сфері за одночасних труднощів оволодіння навичками читання. Отримані результати констатують, що мають місце не тільки прямі способи допомоги дитині у навчанні. Складання корекційної програми на основі формування правильних рухових патернів може бути конструктивною базою для успішної роботи.

Узагальнимо, що у читанні дитина зустрічається 3 появою більш високоорганізованих семантичних і граматичних форм, таким чином управління мовленням переходить 3 предметного рівня на більш високий і з'являється певний мотив до вчинення дії.

\section{Список використаних джерел:}

Alice van de Walle de Ghelcke, A., Skoura, X., Edwards, M.G., Quercia, P. and Papaxanthis, C. Action representation deficits in adolescents with developmental dyslexia. J Neuropsychol. 2021. Vol. 15. P. 215-234. https://doi.org/10.1111/jnp.12220

Azorín E. I., Lobo, P. M., Vergara-Moragues E., Calvo, A. Neuropsychological program of english learning for students with dyslexia. Electronic Journal of Research in Education Psychology. 2018. Vol. 16(45). P. 417. DOI: $10.25115 /$ ejrep.v16i45.2100

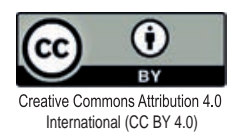


and/or developmental coordination disorder: Are both necessarily worse than one? Child Neuropsychology, 23(4), 422-441. DOI: 10.1080/09297049 .2015.1127339

Narimani, M., Abolghasemi, A., Ilbeigy, R. (2018). The effectiveness of verbal self-instruction training on executive functions and visual motor coordination in children with dyslexia. Journal of Learning Disabilities, 7(2), 72-93. DOI: 10.22098/jld.2018.616

Octávio Moura, Marcelino Pereira, Cláudia Alfaiate, Eva Fernandes, Boavida Fernandes, Susana Nogueira, Joana Moreno, \& Mário R. Simões (2017). Neurocognitive functioning in children with developmental dyslexia and attention-deficit/hyperactivity disorder: Multiple deficits and diagnostic accuracy, Journal of Clinical and Experimental Neuropsychology, 39(3). 296-312. DOI: 10.1080/138 03395.2016 .1225007

Radul, I. G. (2019). Doslidzhennia ehotsentryzmu dytiachoho movlennia v psykholohii [Research of egocentrism of children's speech in psychology]. Insait: psykholohichni vymiry suspilstva: naukovyi zhurnal - Insight: the psychological dimensions of society, Vol. 2. 52-57. https://doi.org/10.32999/2663970X/2019-2-7

Stéphanie Maziero, Jessica Tallet, Stéphanie Bellocchi, Marianne Jover, Yves Chaix \& Mélanie Jucla (2020). Influence of comorbidity on working memory profile in dyslexia and developmental coordination disorder, Journal of Clinical and Experimental Neuropsychology, 42(7). 660-674. DOI: 10.1080/138 03395.2020 .1798880

Tsvetkov, A. V. (2017). Neiropsykholohycheskaia sensomotornaia korrektsyia $\mathrm{v}$ detskom vozraste: poysk metodolohycheskoho statusa [Neuropsychological sensorimotor correction in childhood: the search for methodological status]. Teoryia. Praktyka. Ynnovatsyy - Theory. Practice. Innovations, 7(19), 131-146.

Zasiekina, L. (2018). Neuro-cognitive Underpinning of Co-morbidity between Developmental Dyslexia and Attention-Deficit Hyperactivity Disorder (ADHD). Psycholinguistics, 24(1), 134-148. https://doi.org/10.31470/2309-1797-2018-241-134-148.
Glozman J., Nemeth D. G. The contributions of Luria and Reitan to developmental neuropsychology and to the understanding of neuropsychologically compromised children. Evaluation and Treatment of Neuropsychologically Compromised Children. 2020. Vol. 1(26). DOI: 10.1016/b978-0-12-819545-1.00001-1

González-Valenzuela M., Martín-Ruiz I. Neuropsychological Perspective on Dyslexia. Learning Disabilities [Working Title]. 2021. DOI: 10.5772/intechopen.99386

Кіпаренко О. Сенсорна інтеграція як метод корекції розладів у дітей. Збірник наукових праць “Проблеми сучасної психології, 49, 2020. С. 152176. https://doi.org/10.32626/2227-6246.202049.152-176

Maelle Biotteau, Jean-Michel Albaret, Sandrine Lelong Yves Chaix. Neuropsychological status of French children with developmental dyslexia and/or developmental coordination disorder: Are both necessarily worse than one? Child Neuropsychology. 2017. Vol. 23(4). P. 422-441. DOI: $10.1080 / 0$ 9297049.2015.1127339

Narimani, M., Abolghasemi, A., Ilbeigy, R. The effectiveness of verbal self-instruction training on executive functions and visual motor coordination in children with dyslexia. Journal of Learning Disabilities. 2018. Vol. 7(2). P. 72-93. DOI: 10.22098/jld.2018.616

Octávio Moura, Marcelino Pereira, Cláudia Alfaiate, Eva Fernandes, Boavida Fernandes, Susana Nogueira, Joana Moreno, Mário R. Simões. Neurocognitive functioning in children with developmental dyslexia and attention-deficit/hyperactivity disorder: Multiple deficits and diagnostic accuracy. Journal of Clinical and Experimental Neuropsychology. 2017. Vol. 39(3). P. 296-312. DOI: 10.1080/13803 395.2016.1225007

Радул I. Г. Дослідження егоцентризму дитячого мовлення в психології. Науковий журнал Інсайт: психологічні виміри суспільства, 2, 2019. C. 52-57. https://doi.org/10.32999/2663970X/2019-2-7

Stéphanie Maziero, Jessica Tallet, Stéphanie Bellocchi, Marianne Jover, Yves Chaix, Mélanie Jucla. Influence of comorbidity on working memory profile in dyslexia and developmental coordination disorder. Journal of Clinical and Experimental Neuropsychology. 2020. Vol. 42(7). P. 660-674. DOI: 10.1080/1 3803395.2020 .1798880

Цветков А.В.Нейропсихологическая сенсомоторная коррекция в детском возрасте: поиск методологического статуса. Теория. Практика. Инновации. Vol. 7(19). 2017. С. 131-146.

Zasiekina, L. Neuro-cognitive Underpinning of Co-morbidity between Developmental Dyslexia and Attention-Deficit Hyperactivity Disorder (ADHD). PSYCHOLINGUISTICS. 2018. Vol. 24(1). P. 134-148. https://doi.org/10.31470/2309-1797-2018-241-134-148.

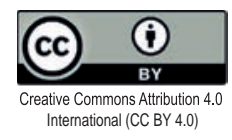

